\title{
Práticas de modelagem matemática e dimensões da aprendizagem da geometria
}

Prácticas de modelación matemática y dimensiones de aprendizaje de geometría

Mathematical modelling practices and dimensions of learning in geometry

\section{Dirceu dos Santos Brito \\ Lourdes Maria Werle de Almeida}

\section{Citar este documento según modelo APA}

Brito, Dirceu dos Santos. e Almeida, Lourdes Maria Werle de. (2021). Practicas de modelagem matemática e dimensiões da aprendizagem da geometría. Revista Actualidades Investigativas en Educación, 21(1), 1-29. Doi. 10.15517/aie.v21i1.42595 


\title{
Práticas de modelagem matemática e dimensões da aprendizagem da geometria
}

Prácticas de modelación matemática y dimensiones de aprendizaje de geometría Mathematical modelling practices and dimensions of learning in geometry

\section{Dirceu dos Santos Brito ${ }^{1}$ Lourdes Maria Werle de Almeida²}

\begin{abstract}
Resumo: Este artigo relata parte da pesquisa de doutorado realizada no Brasil em 2018, cujo escopo consiste em investigar como a aprendizagem da geometria acontece nas práticas de modelagem matemática. Um modelo teórico, propondo seis diferentes dimensões da aprendizagem geométrica em práticas modelagem, é inicialmente apresentado e discutido. Os dados dessa pesquisa, obtidos mediante o desenvolvimento de práticas de modelagem com duas turmas de estudantes do ensino fundamental, permitiram analisar como os estudantes aprendem a utilizar o conceito geométrico de centroide para determinar o centro médio de uma população. Essa análise fenomenológica conclui que a aprendizagem do conceito de centroide acontece pela aquisição de uma estratificação, na qual esse conceito se mostra com os seguintes significados: (i) posição média de uma forma geométrica; (ii) ponto localizado numa figura plana de tal modo que toda reta que passa por ele divide essa figura em duas regiões de mesma área; (iii) ponto de equilibrio de um objeto; (iv) centro de massas dado pela média ponderada da distribuição espacial dessas massas; (v) centro médio ponderado da dispersão espacial de indivíduos. Este artigo conclui que essa estratificação pode ser interpretada como uma estrutura de generalização/metáfora, de modo que a aprendizagem do conceito de centroide, na prática de modelagem, pode ser entendida como a aquisição dessa estrutura, a saber, como a aquisição de uma metáfora linguístico-visual que possibilita investigar e extrair informações acerca do espaço.
\end{abstract}

Palavras-chave: educação, geometria, modelagem, aprendizagem.

Resumen: Este reporta parte de la investigación doctoral realizada en Brasil en 2018, cuyo objetivo es investigar cómo sucede el aprendizaje de la geometría en las prácticas de modelacion. Inicialmente, se presenta y se discute un modelo teórico que propone seis dimensiones diferentes del aprendizaje geométrico en las prácticas de modelacion. Los datos de esta investigación, obtenidos a través del desarrollo de prácticas de modelacion con dos clases de estudiantes de primaria, permitieron analizar cómo los estudiantes aprenden a utilizar el concepto geométrico centroide para determinar el centro promedio de una población. Este análisis fenomenológico concluye que el aprendizaje del concepto centroide ocurre a través de la adquisición de una estratificación, en la cual dicho concepto se manifiesta con los siguientes significados: (i) posición promedio de una forma geométrica; (ii) punto ubicado en una figura plana, de tal manera que cualquier línea recta que la atraviese divide esa figura en dos regiones de la misma área; (iii) punto de equilibrio de un objeto; (iv) centro de masas dado por el promedio ponderado de la distribución espacial de tales masas; (v) centro promedio ponderado de dispersión espacial de los individuos. Este artículo concluye que la estratificación se puede interpretar como una estructura de generalización o metáfora. De modo que el aprendizaje del concepto centroide, en la práctica de la modelacion, puede entenderse como la adquisición de esta estructura; es decir, como la adquisición de una metáfora lingüístico-visual que permite investigar y extraer información sobre el espacio.

Palabras clave: educación, geometría, modelación, aprendizaje.

1 Doutor pelo Programa de Pós-graduação em Ensino de Ciências e Educação Matemática da Universidade Estadual de Londrina, Paraná, Brasil. Endereço eletrônico: dirbrito@gmail.com Orcid: https://orcid.org/0000-0001-8185-3264

2 Docente do Programa de Pós-graduação em Ensino de Ciências e Educação Matemática da Universidade Estadual de Londrina, Paraná, Brasil. Endereço eletrônico: lourdes.@uel.br Orcid: https://orcid.org/0000-0001-8952-1176

Artículo recibido: 30 de junio, 2020

Enviado a corrección: 21 de setiembre, 2020

Aprobado: 19 de octubre, 2020

Los contenidos de este artículo están bajo una licencia Creative Commons 


\begin{abstract}
This article reports part of the doctoral research carried out in Brazil in 2018, whose scope is to investigate how the learning of geometry happens in mathematical modeling practices. A theoretical model, proposing six different dimensions of geometric learning in modeling practices, is initially presented and discussed. The data of this research, obtained through the development of modeling practices with two classes of elementary school students, allowed to analyze how students learn to use the geometric concept of centroid to determine the average center of a population. This phenomenological analysis concludes that the learning of the concept of centroid occurs through the acquisition of a stratification, in which this concept shows itself with the following meanings: (i) average position of a geometric shape; (ii) point located on a flat figure in such a way that any straight line that passes through it divides that figure into two regions of the same area; (iii) an object's equilibrium point; (iv) center of masses given by the weighted average of the spatial distribution of these masses; (v) weighted average center of spatial dispersion of individuals. This article concludes that this stratification can be interpreted as a generalization / metaphor structure, so that learning the concept of centroid, in modeling practice, can be understood as the acquisition of this structure, namely, the acquisition of a metaphor linguistic-visual that makes it possible to investigate and extract information about space
\end{abstract}

Key words: education, geometry, modelling, learning.

\title{
1. Introdução
}

O tema da aprendizagem matemática na escola abrange, segundo D’Amore (2007), questões vinculadas à "arte de conceber e conduzir condições que podem determinar a aprendizagem de um conhecimento matemático por parte de um sujeito". Essas condições, segundo esse autor, "têm que poder ser colocadas em ação e reproduzidas intencionalmente" (D'Amore, 2007). Nesse sentido, essas condições se identificam com as práticas educativas, isto é, as práticas educativas são elas próprias condições de aprendizagem e, portanto, podem ser abordadas como objetos de estudo. Dada uma prática educativa específica pode-se inquirir, por exemplo, como ela intermedeia a aprendizagem de um conhecimento ou perguntar quais são as condições para que essa aprendizagem ocorra e adquira certas qualidades (cognitivas e/ou sociais) desejadas.

Considerar as práticas educativas como objeto de estudo acerca das condições de aprendizagem exige que se explicite o que é entendido por aprendizagem. Segundo D'Amore (2007), a aprendizagem pode ser definida como "um conjunto de modificações de comportamentos" no sentido de "realizações de tarefas solicitadas" que sinalizam para um observador pré-determinado a aquisição de um conjunto de conhecimentos ou competências. Essa sinalização da ocorrência da aprendizagem abrange "a gestão de diversas representações, a criação de convicções específicas, o uso de diferentes linguagens, o domínio de um conjunto de repertórios de referências idôneos, de experiências, de justificações ou de obrigações" (D’Amore, 2007). Colocados em ação, esses elementos são constitutivos das práticas educativas como condições para a aprendizagem. 
Em coerência com esse ponto de vista, compreendemos que uma prática de modelagem matemática $^{3}$ se constitui como um conjunto de condições para a aprendizagem da matemática, mas não apenas da matemática. Como têm mostrado diversos estudos, a aprendizagem em práticas de modelagem acontece a partir da investigação de temas oriundos do mundo conhecido dos estudantes, de modo que essa aprendizagem agrega qualidades cognitivas e sociais que transbordam o domínio estrito do conhecimento matemático (Almeida, 2018; Blum, 2015; Carreira, Baioa e Almaida, 2020; Ferri, 2018).

Em relação à geometria, dois estudos apontam como as práticas de modelagem matemática podem se constituir como um conjunto de condições para a aprendizagem. Em Zapata-Grajales, Cano-Velásquez y Villa-Ochoa (2017) um estudo qualitativo analisa os resultados da aprendizagem geométrica adquirida mediante o desenvolvimento de projetos de modelagem relacionados ao estudo da distribuição das folhas e do crescimento de algumas plantas. Esse estudo mostra que, ao realizar projetos de modelagem alicerçados no estudo das formas e das grandezas geométricas, os estudantes construíram o significado de conceitos geométricos.

Em outro estudo, Zukauskas (2012) apresenta os resultados de uma pesquisa que analisa a motivação dos estudantes em aprender conteúdos de geometria a partir da atividade de construção de embalagens, realizada com estudantes do Ensino Fundamental. Este estudo concluiu que "a atividade desenvolvida extraclasse favoreceu a aprendizagem de conteúdos de geometria, assim como possibilitou que fossem identificados momentos de motivação e de desmotivação dos estudantes durante a sua aplicação" (Zukauskas, 2012, p. 5).

Pensar as práticas de modelagem como um conjunto de condições para a aprendizagem da geometria exige considerar a dicotomia que existe entre aprender a demonstrar teoremas geométricos e aprender a construir modelos geométricos. Aprender a demonstrar, por exemplo, o teorema de Pitágoras e saber justificar a validade dessa demonstração é uma prática que, do ponto de vista epistemológico, difere radicalmente de uma prática em que esse teorema é utilizado para construir um modelo geométrico para uma situação real. Essa dicotomia, apontada em (Houdement e Kuzniak, 2003; Usiskin, 1998), pode indicar limitações das práticas de modelagem matemática para gerar as condições para a aprendizagem dos aspectos axiomáticos da geometria. A existência dessas limitações aponta a necessidade de

\footnotetext{
${ }^{3}$ Daqui em diante denotaremos práticas de modelagem matemática simplesmente como práticas de modelagem.
} 
investigar a seguinte questão: como a aprendizagem da geometria acontece nas práticas de modelagem?

O escopo deste artigo, ao abordar essa questão, reside no aprofundamento da compreensão acerca das condições de aprendizagem da geometria em práticas de modelagem, propondo um modelo teórico que analisa a constituição dessa aprendizagem em termos de habilidades e dimensões. O objetivo desse modelo teórico é possibilitar a investigação acerca de como essas habilidades ou dimensões se manifestam em práticas de modelagem. Tendo em vista o objetivo exposto, este trabalho inicia-se discutindo a noção de prática de modelagem matemática e os argumentos que sustentam essas práticas como condições de aprendizagem da matemática, em geral, e da geometria, em particular. Em seguida, uma discussão acerca da existência de seis habilidades ou dimensões constitutivas da aprendizagem em práticas de modelagem é apresentada. Finalmente, são apresentados os resultados de uma pesquisa empírica, realizada sob o enfoque fenomenológico na qual os dados coletados são analisados mediante reduções sucessivas, ou seja, pela busca de convergências na qual se identifica e analisa o sentido que se manifesta em uma das habilidades ou dimensões da aprendizagem da geometria em uma prática de modelagem.

\section{Das práticas de modelagem matemática à aprendizagem da geometria escolar}

\subsection{As práticas de modelagem matemática}

A modelagem, como ação humana empregada na construção de modelos matemáticos, "consiste, essencialmente na arte de transformar situações da realidade em problemas matemáticos cujas soluções devem ser interpretadas na linguagem usual" (Bassanezi, 2002, p. 24). A modelagem aproxima-se de uma arte porque exige uma ação criativa e não a aplicação de uma teoria ou de um método. O uso de uma teoria ou método, neste caso, consiste numa prática ad hoc, adaptada ao caso específico em estudo.

$\mathrm{Na}$ educação escolar, modelagem é identificada como uma prática voltada para o ensino e a aprendizagem da matemática. O uso do termo prática, neste caso, não busca diferenciar a modelagem de uma teoria, nem sugerir que ela se resume na aplicação de um saber teórico, mas, como esclarece Klüber (2013 p. 96) "ela mesma pode ser uma espécie de teorização que não se fecha em si mesma". Teoria e prática se retroalimentam e, em alguns momentos, se confundem e se complementam (Almeida, Silva e Ramos, 2018). 
A modelagem, como uma prática escolar, costuma ser estruturada numa sequência de etapas (Meyer, Caldeira e Malheiros, 2011). De acordo com Almeida e Vertuan (2014), essa estrutura pode incluir $(i)$ inteiração, na qual os estudantes procuram se familiarizar com um tema a ser investigado; (ii) matematização, fase em que os estudantes buscam traduzir o problema real investigado em um problema matemático; (iii) resolução, os estudantes resolvem o problema matemático; e (iv) interpretação de resultados e validação, momento em que os estudantes devem interpretar a solução do problema matemático em termos do problema real e do tema investigado, validando ou não a solução obtida.

Uma prática de modelagem possui, portanto, uma estrutura voltada para um propósito educativo que pode ser a aprendizagem: ( $i$ ) de um tema específico de matemática; (ii) de um tema qualquer não ligado à matemática; (iii) da própria modelagem matemática. Considerando-se a articulação entre estrutura e propósito, pode-se classificar, como cita Galbraith (2015), as práticas escolares de modelagem em dois tipos: 1) como conteúdo, definida pelo propósito de desenvolver habilidades de construir e utilizar modelos matemáticos de modo que as fases da modelagem são traduzidas em termos de competências ou habilidades cognitivas a serem adquiridas pelos estudantes; 2) como veículo que se caracteriza pelo propósito de "construir modelos para aprender matemática" (Galbraith, 2012, p. 5) e, neste caso, a ênfase está nas características da modelagem que favorecem a aprendizagem da matemática.

\subsection{A aprendizagem da matemática nas práticas de modelagem}

Neste tópico, discutimos alguns argumentos que defendem as práticas de modelagem como condições para a aprendizagem da matemática. De acordo com Swan, Turner, Yoon e Muller (2007), a construção de modelos matemáticos favorece a aprendizagem da matemática porque, primeiro, demanda o uso de diferentes tipos de representações matemáticas e estimula a comunicação entre os estudantes com essas representações. Já Pollak (2015) argumenta que as práticas de modelagem oportunizam a formulação e resolução de questões matemáticas genuínas.

Por sua vez, Halverscheid (2008) entende que as práticas de modelagem promovem a aprendizagem porque a etapa de matematização pode ser identificada com o processo 
epistêmico de abstração ${ }^{4}$, presente na construção de novos conhecimentos em matemática. O trabalho de Halverscheid (2008) identifica elementos de uma epistemologia na estrutura das práticas de modelagem e propõe um quadro teórico para abordar a questão de como a aprendizagem ocorre nessas práticas.

Finalmente, Almeida (2018), ao investigar como os alunos usam a matemática em práticas de modelagem, argumenta que os conceitos ou procedimentos ainda não conhecidos podem ser introduzidos ao mesmo tempo em que conteúdos já conhecidos podem ser acionados. A matematização, sobretudo, segundo a autora, viabiliza a conexão entre conhecimento da matemática e aquele extra matemático, configurando um esquema intelectual em que estes conhecimentos são entrelaçados pelos aprendizes.

\subsection{A aprendizagem da geometria nas práticas de modelagem}

Atividades usualmente desenvolvidas na aprendizagem da geometria podem ser vistas, segundo estudo de Girnat e Eichler (2011), como antagônicas às práticas de modelagem. De fato, este estudo, que investiga crenças de professores de matemática, mostra que professores veem a geometria como mais adequada para explorar problemas que exigem o desenvolvimento do raciocínio lógico-dedutivo e problemas que envolvem demonstrações de teoremas do que para construir modelos e resolver problemas reais. Isto ocorre porque, na visão desses professores, atividades de geometria possuem características contraditórias com as práticas de modelagem, conforme indica a Tabela 1.

Tabela 1

Relação entre atividade de modelagem matemática e atividade de geometria

\begin{tabular}{c|c|c}
\hline Característica & Modelagem matemática & Atividade de geometria \\
\hline $\begin{array}{c}\text { Objeto de estudo } \\
\text { Acesso aos } \\
\text { objetos }\end{array}$ & Situação particular & Teorema ou configuração geral \\
$\begin{array}{c}\text { Construção do } \\
\text { modelo real }\end{array}$ & Com simplificação & Descrições construtivas \\
$\begin{array}{c}\text { Tratamento } \\
\text { matemático }\end{array}$ & $\begin{array}{c}\text { Criação de um modelo } \\
\text { matemático }\end{array}$ & $\begin{array}{c}\text { Utilização de operações, } \\
\text { teoremas e métodos conhecidos }\end{array}$ \\
\hline Validação & Empírica & Argumentos dedutivos \\
\hline
\end{tabular}

Fonte: Construído pelos autores a partir de Girnat e Eichler (2011).

4 O que Halverscheid (2008) propõe, grosso modo, é identificar a fase de matematização com o modelo epistemológico chamado RBC+C. As letras $\mathrm{R}, \mathrm{B}, \mathrm{C}$ e $\mathrm{C}$, referem-se, neste modelo, às ações epistêmicas: Recognizing, Building-with, Constructing e Consolidation. Essas ações constituem o processo chamado de de abstração. 
Esse estudo mostra ainda que, na visão dos professores, a geometria desempenha apenas um papel propedêutico à construção de modelos matemáticos, ou seja, a geometria é usada preferencialmente para estruturar e simplificar uma situação real e não para construir modelos matemáticos (Girnat e Eichler, 2011). Por exemplo, para se investigar a velocidade de propagação da podridão de maçãs acondicionadas em caixas, podemos representá-las por esferas ou círculos, o que permite estruturar e simplificar a abordagem do problema e, com isso, introduzir o uso de equações e funções na etapa de matematização. O uso da geometria, neste caso, antecede a matematização do problema, ou seja, ela é propedêutica à matematização.

Ao assumir uma concepção que identifica geometria como teoria axiomática, os professores investigados expressam uma crença de que as práticas educativas em geometria se caracterizam predominantemente como resolução de problemas envolvendo demonstração de teoremas. O estudo de Girnat e Eichler (2011), consequentemente, alerta para a importância de se discutir uma concepção do conhecimento geométrico que fundamente a investigação da aprendizagem em práticas de modelagem. Corroborando essa posição, diversos outros estudos argumentam que uma compreensão acerca da aprendizagem geométrica está imbricada numa concepção geometria (Atiyah, 2003; Català, 2001; Hardy, 2003).

Uma concepção de geometria, coerente com as práticas de modelagem, deve necessariamente considerar que o conhecimento geométrico tem desempenhado, na história da construção de modelos teóricos da física, o papel de ciência do espaço. Considerar a geometria como ciência do espaço pode ser um problema, uma vez que a noção de espaço é difusa e polissêmica, como mostram seus deferentes usos, que vão desde a geografia até a psicologia. Em matemática, por exemplo, chama-se de espaço estruturas abstratas que pouco tem a ver com a noção de espaço empregada na física. Nas práticas de modelagem, o espaço que interessa é aquele com o qual os estudantes estão familiarizados. Portanto, se queremos assumir que "a geometria é a apreensão do espaço", devemos considerar "esse espaço em que a criança vive, respira e se move. O espaço que a criança deve aprender a conhecer, explorar, conquistar, para poder viver, respirar e mover-se melhor" (Freudenthal, 1973, p. 403).

O espaço, com os qual os estudantes estão familiarizados, inclui o espaço real e físico, tal como o vivenciamos em nosso mundo, mas inclui também o chamado espaço das representações, como a janela de um software geométrico ou uma folha de papel, por exemplo. Essa noção de espaço mantém com a geometria escolar uma relação caracterizada 
por um duplo movimento. O espaço desempenha, num primeiro movimento, uma função epistêmica na constituição das idealidades geométricas. Segundo Husserl (2012), essa constituição se dá mediante um ato intencional chamado de "intuição das essências". Esse ato se fundamenta na intuição sensorial, ou seja, na percepção dos objetos do mundo sensível, mas distingue deste, porque seus objetos visados são de natureza ideal. Imaginar, por exemplo, que uma superfície possa ser lixada e polida cada vez mais até atingir um ponto em que ela não pode mais ser polida, permite a instituição da essência ideal do plano euclidiano (Sokolowski, 2004).

O segundo movimento se dá quando idealidades geométricas são empregadas na matematização do espaço. Além da matematização direta do espaço, que consiste em empregar as idealidades geométricas para investigar qualidades espaço-temporais dos objetos (tamanho, posição, movimento, forma), as idealidades geométricas também possibilitam a matematização das qualidades sensíveis ${ }^{5}$ dos objetos, tais como cor, som, odor, textura, intensidade. As idealidades geométricas se constituem, portanto, num modo linguístico de expressão que outorga existência objetiva e durabilidade a essas qualidades sensíveis. Por exemplo, quando a qualidade sonora dos objetos é modelada por uma curva senoidal, encontramos numa idealidade geométrica, a senoidal, um modo linguístico de expressar uma compreensão acerca da sonoridade. Em síntese, o espaço "esconde" informações que não são diretamente acessíveis e cuja obtenção depende da identificação e estudo de aspectos do espaço traduzíveis em um modelo geométrico,

O entendimento desses dois movimentos (constituição de idealidades geométricas e o matematização do espaço) abre-nos a possibilidade de caracterizar a aprendizagem geométrica em práticas de modelagem como a apreensão/aquisição de um modo linguístico de expressar e tornar objetiva uma compreensão acerca do espaço (Grigoraş, Garcia e Halverscheid, 2011). Aprender geometria em uma prática de modelagem significa, portanto, apreender um modo linguístico de extrair informações "escondidas" no espaço e expressar uma compreensão objetiva sobre elas. Caracterizar a aprendizagem geométrica em práticas de modelagem em função do tipo de informação que se busca extrair do espaço e do modo como se pode extrair essa informação é o tema do próximo tópico.

\footnotetext{
5 Husserl (2012) chama essas qualidades de plena, plural de plenum que em latim significa completo ou pleno. 0 plenum sensível é "aquilo que se apresenta nas chamadas qualidades 'específicas' dos sentidos, cor som, odor e similares, em gradações próprias” (Husserl, 2012, p. 22).
} 


\subsection{Dimensões constituintes da aprendizagem da geometria}

Utilizando o estudo de Thompson e Yoon (2007), que propõem uma taxonomia de seis situações que demandam a construção de um modelo numa prática de modelagem, vamos propor aqui um quadro teórico que identifica seis dimensões da aprendizagem da geometria mediada por práticas de modelagem. Essas dimensões podem ser entendidas como as habilidades constituintes dessa aprendizagem que se diferenciam em função do tipo de informação que se busca extrair do espaço e do modo como se pretende obtê-la numa modelagem. Esse quadro teórico identifica seis tipos de informação que se busca extrair do espaço associados, respectivamente, a seis modos distintos de extrair esses tipos de informação (ver Figura 1).

Figura 1

Seis dimensões da aprendizagem geométrica em práticas de modelagem

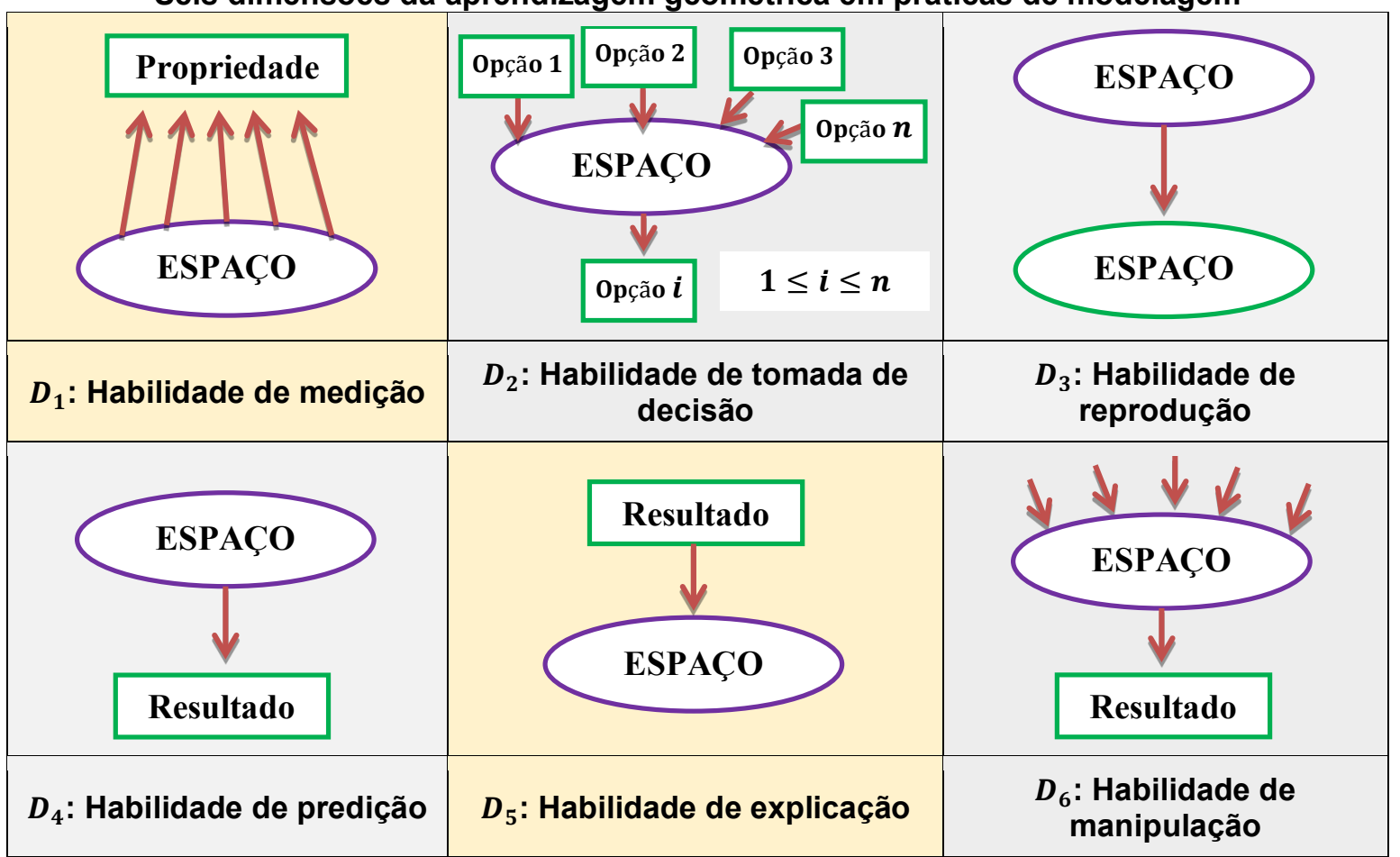

Fonte: Inspirado em Thompson e Yoon (2007)

Dimensão 1 - habilidade de medição: a informação que se busca, neste caso, é a medida de alguma propriedade ou de uma qualidade do espaço que não pode ser determinada diretamente e, por isso, o modo de obtê-la passa pelo desenvolvendo um modelo geométrico que gera essa propriedade. Um exemplo clássico disso é a obtenção da altura da pirâmide Quéops, no Egito, pelo matemático grego Thales que utilizou comprimentos de sombras para construir um modelo geométrico baseado em triângulos semelhantes. 
Dimensão 2 - habilidade de tomada de decisão: a informação que se busca, neste caso, é uma maneira de fazer e justificar uma escolha dentre várias opções que dependem de características espaciais. Assim, se existem várias opções e apenas uma deve ser escolhida, um modelo geométrico pode desenvolvido para avaliar os prós e os contras de cada opção de modo que uma escolha justificada possa ser feita. Por exemplo, se precisamos avaliar a escolha do formato de uma embalagem para um produto, construir um modelo geométrico pode nos ajudar, informando sobre a otimização do volume, minimização do custo de produção, armazenamento e transporte.

Dimensão 3 - habilidade de reprodução: aqui, a informação procurada é um "molde" que possibilita a construção de uma réplica de algum objeto. A construção de um modelo geométrico, neste caso, objetiva, traduzir as características espaciais desse objeto em termos de instruções, tendo em vista a sua reprodução. Por exemplo, para investigar a dispersão de poluentes num rio, podemos precisar construir sua "réplica" e simular seu comportamento. Neste caso, a construção de um modelo geométrico pode ajudar a estimar o fluxo de água, informando sobre a forma do corte transversal desse rio.

Dimensão 4 - habilidade de predição: se variamos certas condições ou "variáveis" espaciais de um objeto, que resultados/consequências isso pode acarretar? Se essas condições ou "variáveis" não podem ser manipuladas diretamente, então um modelo geométrico pode informar acerca do comportamento desse objeto sob condições desejadas. Por exemplo, se desejamos investigar o efeito, no lançamento oblíquo de objetos, da variação do ângulo de inclinação do lançamento, um modelo geométrico que simule a trajetória desse objeto pode informar acerca da altura ou da distância atingida por esse objeto.

Dimensão 5 - habilidade de explicação: se algum resultado incomum do espaço é observado, um modelo geométrico pode ser desenvolvido para explicar como o sistema produziu esse resultado incomum. A informação buscada, neste caso, são as condições ou propriedades do espaço capazes de gerar o resultado observado. Por exemplo, um lápis colocado num copo de água parece "quebrado" devido a refração da luz. A construção de um modelo geométrico para a trajetória dos raios de luz ajuda a explicar o efeito da refração.

Dimensão 6 - habilidade de manipulação: aqui, a informação procurada refere-se a como manipular o espaço para que ele produza um resultado desejado. Um modelo geométrico, neste caso, pode ser construído para saber como e sobre quais condições ou sobre quais propriedades do espaço devemos intervir para que um efeito esperado seja produzido. Por exemplo, se precisamos construir uma rede caminhos para interligar um 
número finito de lugares, então a construção de um modelo geométrico pode auxiliar na identificação das propriedades que minimiza o comprimento total dessa rede.

Como mostra a Tabela 2, cada uma dessas habilidades corresponde a uma classe de problemas de modelagem, ou seja, uma habilidade $H_{i}$ é requerida para lidar com uma classe $C_{i}$ de problemas que são equivalentes, considerando-se o tipo de informação que se busca extrair do espaço e o modo como essa informação pode ser obtida. Se numa prática de modelagem os estudantes investigam um espaço $E$ com uma geometria $G$, dizemos que $G$ é um modelo matemático de $E$, se $G$ permite aos estudantes extrair informações de $E$ e expressar e tornar objetiva uma compreensão acerca de $E$. Aprender geometria em práticas de modelagem significa, em síntese, desenvolver cada uma dessas seis habilidades e adquirir, com isso, um modo linguístico de expressar e tornar objetiva uma compreensão acerca do espaço.

\section{Tabela 2}

Relação entre classes de problemas e suas respectivas habilidades de aprendizagem

\begin{tabular}{|c|c|}
\hline Classes de Problemas & Habilidades da Aprendizagem \\
\hline $\begin{array}{l}\boldsymbol{C}_{\mathbf{1}} \text { : Como gerar uma propriedade de } \mathrm{E} \text {, tendo } \\
\text { em vista sua mensuração? }\end{array}$ & $\begin{array}{l}H_{1} \text { : Elaborar configurações ou procedimentos } \\
\text { geométricos que permitem estimar a medida de } \\
\text { uma propriedade de } \mathrm{E} \text {. }\end{array}$ \\
\hline $\begin{array}{l}\boldsymbol{C}_{2} \text { : Que propriedades de } \mathrm{E} \text { devo considerar } \\
\text { para avaliar uma escolha dentre várias } \\
\text { opções? }\end{array}$ & $\begin{array}{l}\mathrm{H}_{2} \text { : Identificar e/ou desenvolver modelos } \\
\text { geométricos que auxiliem na avaliação de uma } \\
\text { tomada de decisão. }\end{array}$ \\
\hline $\begin{array}{l}\boldsymbol{C}_{3} \text { : Que propriedades essenciais de E devem } \\
\text { ser consideradas, tendo em vista a } \\
\text { construção de uma réplica de E? }\end{array}$ & $\begin{array}{l}H_{3} \text { : Traduzir as características essenciais de } \mathrm{E} \\
\text { em termos de propriedades geométricas que } \\
\text { funcionem como instruções para a reprodução de } \\
\mathrm{E} \text {. }\end{array}$ \\
\hline $\begin{array}{l}\boldsymbol{C}_{4}: \text { Que resultados ou consequências pode- } \\
\text { se prever para } E \text {, supondo que E possuísse } \\
\text { determinadas propriedades? }\end{array}$ & $\begin{array}{l}H_{4}: \text { Desenvolver modelos geométricos que } \\
\text { permitem prever o comportamento de } \mathrm{E} \text { sob } \\
\text { condições desejadas. }\end{array}$ \\
\hline $\begin{array}{l}\boldsymbol{C}_{\mathbf{5}} \text { : Que propriedades } \mathrm{E} \text { deveria possuir para } \\
\text { que determinado efeito ou resultado incomum } \\
\text { em } \mathrm{E} \text { possa ser explicado? }\end{array}$ & $\begin{array}{l}\mathrm{H}_{5} \text { : Construir modelos geométricos que explicitem } \\
\text { as propriedades de } \mathrm{E} \text { que explicam um efeito ou } \\
\text { resultado incomum em } \mathrm{E} \text {. }\end{array}$ \\
\hline $\begin{array}{l}\boldsymbol{C}_{6} \text { : Como e sobre quais propriedades de } \mathrm{E} \\
\text { devo intervir para obter um resultado } \\
\text { desejado em E? }\end{array}$ & $\begin{array}{l}H_{6} \text { : Criar e explorar modelos geométricos que } \\
\text { explicitem propriedades e procedimentos para } \\
\text { produzir um efeito desejado em } \mathrm{E} \text {. }\end{array}$ \\
\hline
\end{tabular}

Fonte: Elaborado pelos autores (2018) 


\section{Metodologia}

\subsection{Enfoque}

Este artigo apresenta uma investigação da manifestação das dimensões ou habilidades constituintes da aprendizagem da geometria em práticas de modelagem, a partir de um enfoque fenomenológico. Esse enfoque é uma modalidade da pesquisa qualitativa que se distingue das pesquisas qualitativas em geral pelo modo muito particular como compreende a noção de qualidade. A qualidade que interessa à fenomenologia não é, como observa Bicudo (2011, p. 18), aquela "tomada como já dada e pertinente ao objeto", mas aquela que se mostra na percepção, ou seja, aquela que é percebida no par fenômeno/percebido.

Investigar a qualidade percebida no par fenômeno/percebido exige, segundo Giorgi (2014), três movimentos: a descrição, a redução fenomenológica e a busca das essências. Por descrição entende-se o modo de dar conta do que é percebido na percepção e exige "utilizar a linguagem, de modo articular os objetos intencionais da consciência nos limites das coerções impostas pela evidência intuitiva" (Giorgi, 2014, p. 391). A descrição "não opera por abstração sob abstração, mas com o compreendido nos vividos reduzidos em intuição pura" (Bicudo, 2011, p.45).

O movimento de redução, por sua vez, requer que a atenção dirigida às características ou qualidades do objeto ceda lugar à atenção dirigida aos modos subjetivos de doação desse objeto. Reduzir, em sentido fenomenológico, significa suspender os juízos prévios ou pressuposições e descrever aquilo que se mostra, exatamente como se mostra, sem recair em explicações, construções ou interpretações, isto é, "sem teorias sobre sua explicação causal e tão livre quanto possível, de pressupostos e de preconceitos" (Bicudo, 1994, p. 15).

Por fim, o movimento de busca de essências implica em não se deter em descrições de individualidades, de singularidades da experiência vivida pelo sujeito, mas "mostrar as estruturas em que a experiência relatada se dá, deixando transparecer, nessa descrição, as suas estruturas universais" (Bicudo, 2011, p. 46). Buscar essências visa, portanto, transcender o que está individualmente descrito e avançar em direção à estrutura do fenômeno, isto é, um sentido fundamental que se mantém mais duradouramente num determinado contexto e sem o qual o fenômeno não poderia se apresentar tal como ele é. Buscar uma essência significa, em síntese, buscar uma "identidade constante que contém as variações que um fenômeno é capaz de sofrer, e que as limita" (Giorgi, 2014, p. 395). 


\subsection{Participantes}

Buscar uma compreensão, sob o enfoque fenomenológico, da aprendizagem da geometria que se mostra em práticas de modelagem exige uma abertura para esse fenômeno. Por conta dessa exigência, desenvolvemos uma pesquisa, em nível de doutorado, no período de 2017/2018, em uma escola pública da educação básica do estado do Paraná/Brasil, na qual o primeiro autor deste artigo trabalha como professor. Situada na periferia da cidade de Londrina, essa escola oferece ensino fundamental e médio e atende jovens oriundos da população pobre. Os estudantes participantes da pesquisa pertencem à duas duas turmas regulares do $9^{\circ}$ ano do ensino fundamental com cerca de 35 estudantes cada. Como o professor de matemática dessas duas turmas desenvolvia a pesquisa de doutorado, a escolha dos estudantes participantes não se deu de maneira aleatória, nem a participação deles foi voluntária, mas foi solicitada como qualquer outra atividade regular na escola. A pesquisa foi realizada durante cinco semanas com cinco aulas de matemática por semana. Em cada aula, os estudantes dessas turmas eram organizados em pequenos grupos para investigar, sob orientação do professor, um tema. Ao todo, três temas foram investigados.

O primeiro tema, inspirado no artigo de Mason (2001), trata do equilíbrio de uma latinha de refrigerante. A questão, investigada pelos estudantes é porque a latinha fica em equilíbrio, apoiada sobre sua borda numa superfície horizontal, quando contém uma quantidade de líquido entre $50 \mathrm{ml}$ e $200 \mathrm{ml}$. O segundo tema aborda os diferentes tipos de amarrações de cadarços de tênis. Aqui, os estudantes foram convidados a investigar como cada tipo de amarração influencia no comprimento do cadarço que "sobra", ou seja, as pontas do cadarço que utilizadas para fazer o laço ou dar o nó na amarração. O terceiro tema aborda o problema da construção de uma escola polo para receber estudantes de outras quatro escolas de uma região da cidade. Foram investigadas várias questões: onde deveria localizar essa nova escola, levando em conta a relação de proximidade com as outras quatro? Que forma geométrica deve possuir cada sala de aula para otimizar a ocupação dos estudantes e minimizar custos? 


\subsection{Técnica de coleta dos dados}

Para a coleta de dados, dois instrumentos foram utilizados: ( $i$ ) um relato individual no qual o estudante expressa discursivamente ${ }^{6}$ como percebe sua aprendizagem geométrica, e (ii) a filmagem da atuação dos estudantes nas práticas de modelagem, de modo a registrar suas falas, gestos, comunicações intersubjetivas, movimentações corporais, escritos e desenhos. A partir da leitura atenta dos relatos individuais e das transcrições dos vídeos, destacamos passagens que se mostraram importantes para a compreensão da aprendizagem geométrica. Essas passagens são chamadas por Bicudo (2011) de unidades de sentido. Neste artigo, exibimos dois tipos de unidades de sentido: unidades extraídas dos relatos individuais dos estudantes, que chamamos de quadros de discursos; unidades obtidas das transcrições das filmagens, que chamamos de cenas significativas.

\subsection{Técnica de análise dos dados}

A análise dos dados consiste em destacar, das unidades de sentido, os significados percebidos que respondem ao que está sendo interrogado na investigação. Isto é, procuramos articular, em asserções afirmativas, as unidades de significado que se mostram em cada unidade de sentido. Para facilitar a referência a essas asserções ou unidades de significado, vamos codificá-las, utilizando a letra $\boldsymbol{S}$ maiúscula seguida de dois índices (Por exemplo, o código $S_{21}$ identifica a unidade de significado 1 extraída da unidade de sentido 2).

A articulação desses significados em asserções afirmativas se constitui numa primeira redução e visa explicitar convergências, isto é, visa identificar o que esses significados têm em comum, desvelando os invariantes do fenômeno investigado. Neste trabalho, portanto, a obtenção desses invariantes ocorre como consequência de um movimento sucessivo de reduções que se inicia com a articulação dos significados expressos nos quadros de discursos e na cena significativa e que avança com busca da transcendência dos aspectos individuais desses significados, isto é, com a busca das convergências que revelam a estrutura do fenômeno.

\footnotetext{
6 Esses relatos foram obtidos mediante a solicitação feita numa folha pautada contendo em seu cabeçalho o seguinte enunciado: tente se lembrar das coisas que você aprendeu nessa atividade e descreva, o mais detalhadamente que você puder, as situações nas quais essa aprendizagem ocorreu para você.
} 


\subsection{A unidade de análise}

Neste artigo, como já mencionamos, vamos apresentar a análise da aprendizagem da geometria que se mostrou em uma das três práticas de modelagem realizadas com os estudantes. A prática aqui analisada foi motivada pela necessidade de discutir com os estudantes um local adequado para a construção de uma escola de período integral para o ensino médio. A região já possui quatro escolas. Mas, consideramos com os estudantes que essas escolas atenderiam somente estudantes do ensino fundamental, de modo que a construção de uma nova escola para o ensino médio deveria ser feita num local próximo às quatro já existentes. A questão, portanto, a ser investigada pelos estudantes é que local seria mais adequado para construir essa nova escola de modo a minimizar sua distância até essas quatro escolas.

Os estudantes, organizados em pequenos grupos de 4 a 5 membros, receberam um mapa da região indicando as quatro escolas e um texto contendo informações sobre o número de estudantes matriculados em cada uma delas, como mostra a figura 2. Com esses dados, cada grupo de estudantes procuraram estabelecer critérios para determinar um local para a construção da nova escola, levando em conta as distâncias entre as quatro escolas existentes e o número de estudantes que cada uma delas atende.

Figura 2

Informações disponibilizadas para os estudantes do Brasil em 2018

A região representada no mapa possui quatro escolas de ensino fundamental, indicadas por A, B, C e $D$, sabendo que atendem atualmente $580,660,560,550$ alunos, respectivamente.

Sabendo que uma nova escola deve ser construída para receber alunos das quatro escolas existentes, investigue as questões:

a) Que critérios deveriam ser considerados para determinar a localização dessa nova escola?

b) Como determinar essa localização?

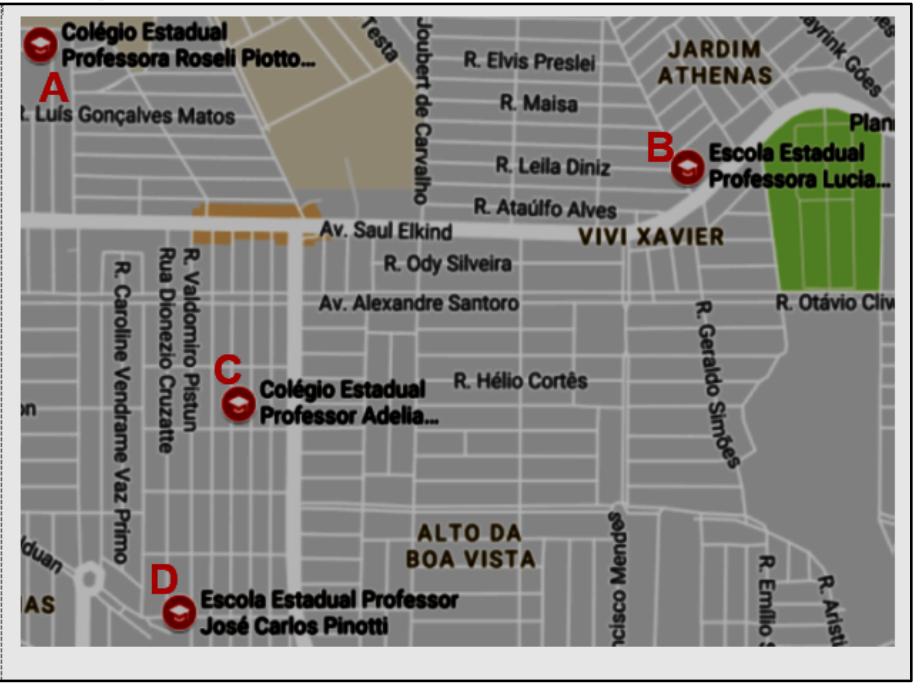

Fonte: Dados da pesquisa (2018) 
O encaminhamento metodológico adotado e as orientações do professor conduziram os estudantes a perceberem que o problema de determinar a localização da nova escola consiste em determinar o centro médio de uma população. Os grupos consideraram cada escola como uma sub-região e a quantidade de alunos matriculados em cada escola foi tomada como a população dessa sub-região. Utilizando um sistema de coordenadas cartesianas sobre o mapa da figura 2 e o número de estudantes de cada escola como peso, foi possível determinar a localização da nova escola calculando a média ponderada das coordenadas das quatro escolas.

Ao elaborar esse modelo geométrico, os estudantes utilizaram a noção de centroide de uma figura plana para determinar o centro de uma população. Isto é, os estudantes utilizaram uma "geometria" para extrair uma informação acerca do espaço dado na representação das escolas no mapa. Ao utilizar um modelo geométrico para identificar a localização que a nova escola deveria ter, tendo em vista a minimização das distâncias, os estudantes precisaram determinar propriedades do espaço, tendo em vista um resultado desejado. Portanto, o problema investigado pelos estudantes pertence à classe $C_{6}$ e, para resolvê-lo, os estudantes desenvolveram a habilidade $H_{6}$. Neste trabalho de pesquisa, portanto, vamos nos concentrar na análise fenomenológica de como a habilidade $H_{6}$ se mostrou nessa prática.

\section{Resultados}

\subsection{Quadros de discursos}

Nesta seção, vamos apresentar a análise de três quadros de discurso. Esses quadros evidenciam indícios de como os estudantes percebem sua própria aprendizagem na modelagem ao descrever como realizaram os procedimentos para determinar o centro de uma região representada num mapa. Nesses quadros de discurso os estudantes descrevem como empregaram a noção de centro geométrico ou centroide para determinar o centro de uma população. Vamos apresentar a imagem do discurso dos estudantes seguida a transcrição literal do relato do estudante, constituindo esses dois elementos uma unidade de sentido (Ver Figura 3, Figura 4, Figura 5). Por fim, procuramos articular, em asserções afirmativas, as unidades de significado que se mostram no discurso. 
Figura 3

Unidade de Sentido 1 - Quadro de Discurso com a opinião de um estudante do Brasil em 2018

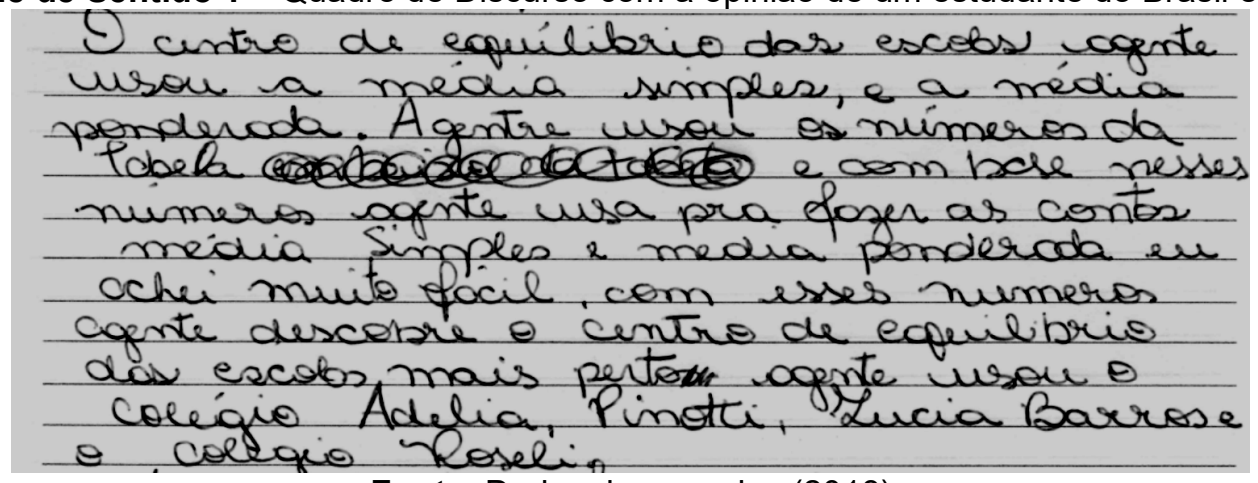

Fonte: Dados da pesquisa (2018)

\section{Transcrição}

O centro de equilíbrio das escolas a gente usou a média simples e a média ponderada. A gente usou os números da tabela ... e com base nesses números a gente usa pra fazer as contas média simples e média ponderada ... eu achei muito fácil, com esses números a gente descobre o centro de equilíbrio das escolas mais perto ... a gente usou o colégio Adélia, Pinoti, Lúcia Barros e colégio Roseli.

\section{Unidades de Significado}

$\boldsymbol{S}_{11}$ : O estudante relata a aprendizagem do procedimento de organizar numa tabela as coordenadas do local e o número de estudantes de cada escola e, com isso, efetuar o cálculo do centro de populações das quatro escolas.

$\boldsymbol{S}_{12}$ : O estudante afirma que o cálculo do centro de populações das escolas foi feito usando a média aritmética das coordenadas e a média ponderada que, neste caso, utiliza como pesos as quantidades de alunos de cada escola.

$S_{13}$ : O estudante complementa que a realização do cálculo foi fácil e indica compreender o significado que esse cálculo possui na determinação de uma localização que leva em conta a proximidade com as quatro escolas.

$\boldsymbol{S}_{14}$ : O estudante vê que sua aprendizagem se deu como a aquisição de um procedimento de cálculo e de uma interpretação geométrica dos resultados obtidos nesse procedimento. 
Figura 4

Unidade de Sentido 2 - Quadro de Discurso com a opinião de um estudante do Brasil em 2018

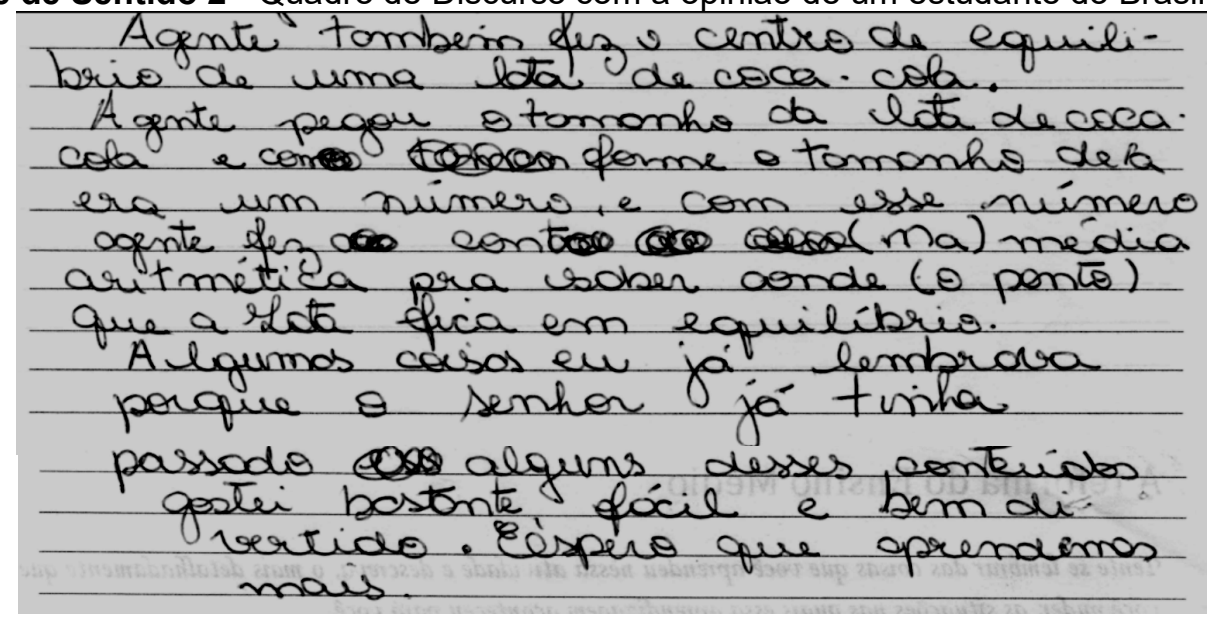

Fonte: Dados a pesquisa (2018)

\section{Transcrição}

A gente também fez o centro de equilíbrio de uma lata de Coca-Cola. A gente pegou o tamanho da lata de Coca-Cola e conforme o tamanho dela era um número, e com esse número a gente fez a conta ... (ma) média aritmética prá saber onde (o ponto) que a lata fica em equilíbrio. Algumas coisas eu já lembrava porque o senhor já tinha passado ... alguns desses conteúdos gostei bastante, fácil e bem divertido. Espero que aprendemos mais.

\section{Unidades de Significado}

$S_{21}$ : O estudante vê que sua aprendizagem se vincula com o que aprendeu na primeira prática de modelagem na qual foi investigado porque a latinha permanece em equilíbrio quando sua borda é apoiada sobre uma superfície horizontal e seu conteúdo líquido está entre $50 \mathrm{ml}$ e $200 \mathrm{ml}$.

$\boldsymbol{S}_{22}$ : O estudante relata que aprendeu a calcular o centro de equilíbrio da lata de refrigerante inclinada, utilizando as coordenadas cartesianas dos vértices da imagem da lata.

$\boldsymbol{S}_{23}$ : O estudante destaca a importância de utilizar a geometria aprendida na prática de modelagem da latinha de refrigerante porque o estudante empregou o que aprendeu nela para calcular o centro das populações.

$\boldsymbol{S}_{\mathbf{2 4}}$ : O estudante direciona sua descrição para o cálculo do centro de equilíbrio da lata utilizando um sistema de coordenadas cartesianas e cita que aprendeu uso da média aritmética para determinar esse centro. 
Figura 5

Unidade de Sentido 3 - Quadro de Discurso com a opinião de um estudante do Brasil em 2018

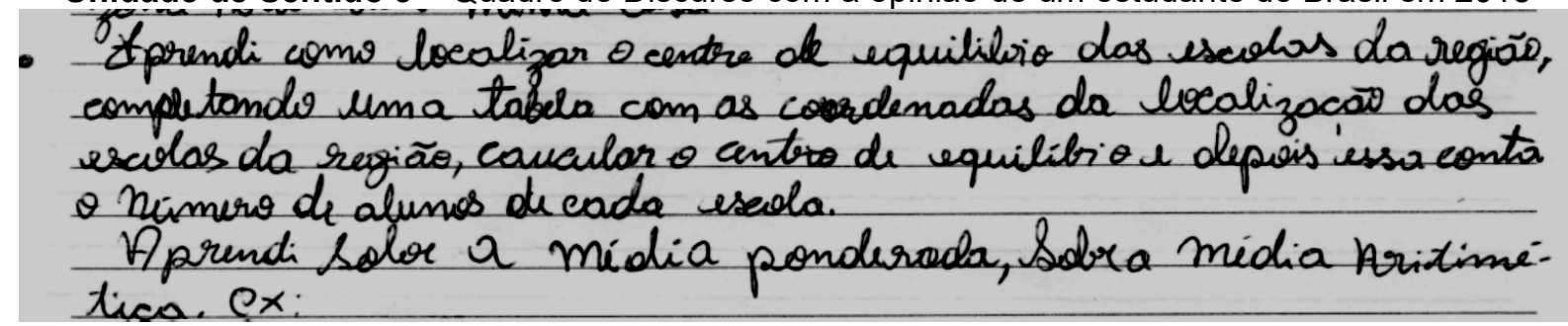

Fonte: Dados da pesquisa (2018)

\section{Transcrição}

Aprendi como localizar o centro de equilibrio das escolas da região, completando uma tabela com as coordenadas da localização das escolas da região, calcular o centro de equilíbrio e depois usar (na) conta o número de alunos de cada escola. Aprendi sobre a média ponderada, sobre a média aritmética.

\section{Unidades de Significado}

$\boldsymbol{S}_{31}$ : O estudante descreve que aprendeu como localizar o centro de equilíbrio das escolas da região completando uma tabela com as coordenadas e com o número de alunos de cada escola.

$S_{32}$ : O estudante diz que aprendeu a calcular o centro com a média aritmética e com a média ponderada e destaca a aprendizagem dos procedimentos de cálculo para determinar o centro de equilíbrio das escolas.

$\boldsymbol{S}_{33}$ : O estudante indica perceber a relação entre esses procedimentos e o significado de centro de equilíbrio.

$\boldsymbol{S}_{34:}$ O estudante vê que sua aprendizagem se dá como uma aquisição de procedimentos metódicos que são empregados para obter um resultado.

\subsection{Cena significativa}

A cena significativa analisada mostra um grupo de estudantes procurando justificar os procedimentos adotados para localizar no mapa o centro médio de populações das quatro escolas. Esses estudantes sabiam como determinar o centroide de figuras simples tais como triângulos e quadriláteros notáveis, pois aprenderam esses procedimentos na prática anterior de modelagem relativa à latinha de refrigerante. Nessa prática de modelagem os alunos 
aprenderam também a determinar o baricentro de um triângulo calculando a média aritmética das coordenadas dos seus vértices. Esse procedimento é utilizado pelos estudantes para determinar o "centroide" das quatro escolas, ou seja, utilizando o número de matriculados em cada escola como peso, o grupo determinou o centro das escolas com média ponderada. A cena inicia-se com o professor solicitando ao grupo que explique o procedimento adotado.

Figura 6

Unidade de Sentido 4 - Cena Significativa da atividade desenvolvida com os estudantes

Prof.: Então mostra aí, vocês todos aí, mostra onde ficou localizado o centro com a média simples (média aritmética)?

Ana: Aqui, ó no 6 e 7,2 (Ana mostra no mapa o centroide localizado no mapa pelas coordenadas $x=6$ e $y=7,2$, ver figura $6 a)$,

Figuras 6a e Figura 6b, respectivamente.
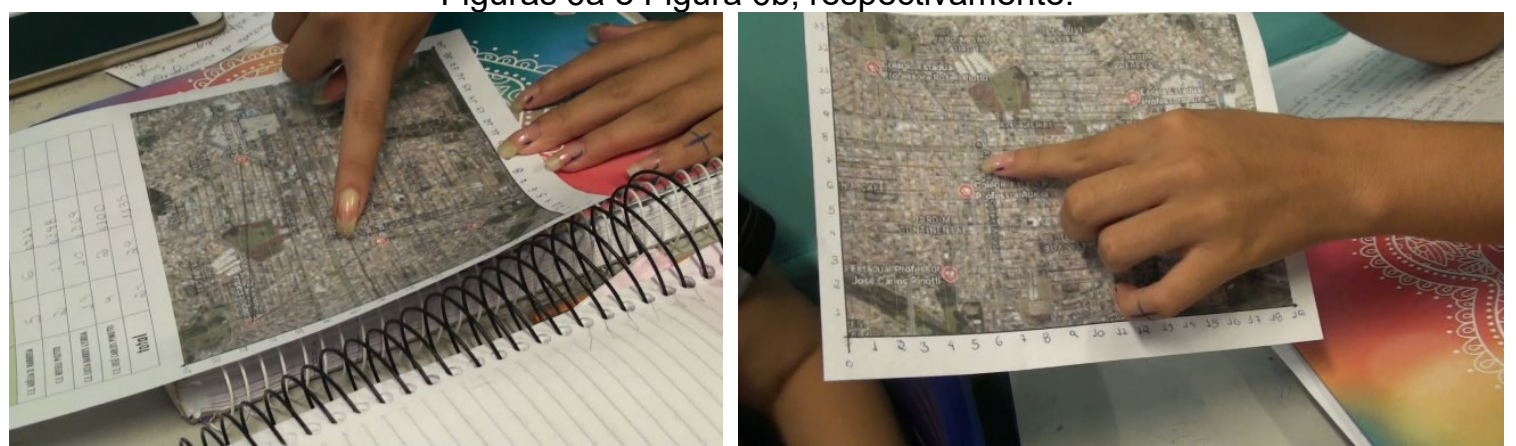

Fonte: Dados da pesquisa (2018)

Prof.: E o da média ponderada? Onde tá localizado?

Ana: A gente não marcou ainda, mas deu no 6 ao 8 (coordenadas $\mathrm{x}=6 \mathrm{e} \mathrm{y}=8$ ).

Prof.: Ah, subiu um pouquinho, né. Marca aí prá você ver. Por que vocês acham que a média ponderada subiu um pouquinho.

Ana: Porque as escolas, olha só, tem que ver o número de alunos das escolas. As escolas que tem mais alunos é o Adélia, o Roseli e depois o Lúcia Barros... tem mais alunos prá cima, por isso, a média ponderada dá aqui em cima. (Ana mostra no mapa onde se localiza o centro das quatro escolas, ver figura $6 b$ )

Pedro: Mas, olhando no mapa, a diferença é pequena. Subiu só um pouquinho, nem faz diferença se a escola ficar no 6 e 7,2 ou no 6 e 8 .

Prof.: É, a diferença é muito pequena, mesmo. Mas, por que isso acontece?

Ana: Veja aqui ó ... (mostrando os cálculos com a média ponderada) ...

$$
\begin{aligned}
& x=\frac{5 \times 417+2 \times 348+13 \times 369+4 \times 100}{417+348+369+100}=\frac{7978}{1234}=6,4 \\
& y=\frac{6 \times 417+11 \times 348+10 \times 369+2 \times 100}{417+348+369+100}=\frac{10220}{1234}=8,2
\end{aligned}
$$

Ana: É que o número de alunos é aproximado. Ó, o Adélia tem 417, o Roseli tem 348, o Lúcia Barros tem 308 e o Pinotti, 190. O único diferente é o Pinotti, por isso, que ficou quase igual (a média aritmética das coordenadas ficou aproximadamente igual a média ponderada).

Fonte: Dados da pesquisa (2018) 


\section{Unidades de Significado}

$\boldsymbol{S}_{41}$ : A cena mostra como os estudantes reinterpretaram o problema de determinar o centro geométrico de figuras planas, isto é, ao invés de utilizarem construções geométricas, os estudantes passaram a empregar um sistema de coordenadas cartesianas e, com isso, interpretaram a solução desse problema em termos de média aritmética e média ponderada das coordenadas de vértices de figuras geométricas.

$\boldsymbol{S}_{42}$ : A cena mostra que, ao utilizar coordenadas cartesianas, os estudantes puderam reinterpretar o problema de determinar o centro geométrico de uma figura. Da ideia de centro geométrico, os estudantes transitaram para a ideia de centro de populações, isto é, da ideia de centro como um local de equidistância ou como ponto em que retas seccionam polígonos em áreas iguais (ideia de centroide), os estudantes puderam compreender o centro como ponto que otimiza distâncias entre indivíduos; como ponto de equilíbrio de um população.

\subsection{Buscando convergências}

As unidades de significado expressas nos três quadros de discursos e na cena significativa remetem a manifestação da aprendizagem da noção geométrica de centroide. Porém, pode-se inferir que esse conceito não aparece exatamente do mesmo modo em cada uma dessas unidades de significado. Vamos, nesta seção, procurar mostrar esses diferentes modos de aparecer do conceito de centroide e como esses modos se mostram como convergência das unidades de significado. Na tabela 3 , mostramos como se dá essa convergência.

A tabela 3 ilustra como as unidades de significado convergem para cinco modos $\left(\boldsymbol{M}_{1}, \ldots, \boldsymbol{M}_{5}\right)$ pelos quais o conceito de centroide se mostra na prática de modelagem. A leitura atenta desses cinco modos, buscando compreender as relações que eles mantêm entre si, indicam que $\left(\boldsymbol{M}_{1}, \ldots, \boldsymbol{M}_{5}\right)$ se constitui numa estratificação da aprendizagem do conceito de centroide na prática de modelagem considerada, de modo que a aprendizagem desse conceito se dá como a aquisição dessa estratificação. 
Tabela 3

Relação entre classes de problemas e suas respectivas habilidades de aprendizagem

\begin{tabular}{|c|c|}
\hline Unidades de Significado & Convergência de modos do conceito geométrico de centroide \\
\hline$S_{21}, S_{22}, S_{41}$ & $\begin{array}{l}M_{1}: \text { o centroide se mostra como uma posição média de uma forma } \\
\text { geométrica. }\end{array}$ \\
\hline$S_{22}, S_{23}$ & $\begin{array}{l}M_{2} \text { : o centroide de uma figura geométrica plana se mostra como } \\
\text { sendo o ponto com a propriedade de que toda reta que passa por } \\
\text { ele divide essa figura em duas regiões de mesma área. }\end{array}$ \\
\hline$S_{13}, S_{31}, S_{33}$ & $\boldsymbol{M}_{3}$ : o centroide se mostra como um ponto de equilíbrio de um objeto. \\
\hline$S_{24}, S_{41}, S_{34}, S_{12}$ & $\begin{array}{l}M_{4} \text { : o centroide se mostra como um centro de massas dado pela } \\
\text { média ponderada da distribuição espacial dessas massas. }\end{array}$ \\
\hline$S_{11}, S_{24}, S_{32}, S_{42}$ & $\begin{array}{l}M_{5}: \text { o centroide se mostra como um centro médio ponderado da } \\
\text { dispersão espacial de indivíduos. }\end{array}$ \\
\hline
\end{tabular}

Fonte: Dados da pesquisa (2018)

A afirmação de que a aprendizagem do conceito de centroide se dá pela aquisição da estratificação $\left(\boldsymbol{M}_{1}, \ldots, \boldsymbol{M}_{5}\right)$, pode ser compreendida de duas maneiras. Pode-se entender que essa aprendizagem se apresenta como a realização de uma generalização; de modo que aprender a investigar o "centroide da população" se dá como generalização da aprendizagem do centroide de uma figura geométrica plana. Outra compreensão possível é que a aquisição da estratificação $\left(\boldsymbol{M}_{1}, \ldots, \boldsymbol{M}_{5}\right)$ se mostra como o desenvolvimento de uma metáfora; de modo que aprender o conceito de centroide consiste em dominar o uso dessa noção como uma metáfora linguística-visual para investigar o "centroide da população".

O esquema apresentado na figura 7 procura mostrar como a estratificação $\left(\boldsymbol{M}_{1}, \ldots, \boldsymbol{M}_{5}\right)$ converge para a estrutura generalização/metáfora expressa uma compreensão acerca da aprendizagem da geometria em práticas de modelagem matemática. No que se segue, vamos apresentar uma interpretação dessa estrutura a partir do modelo teórico discutido na seção 2.4 deste artigo. Como a prática de modelagem desenvolvida envolve predominantemente a dimensão ou habilidade $H_{6}$, nossa interpretação aborda particularmente como a estrutura generalização/metáfora se relaciona com a dimensão ou habilidade $H_{6}$ do modelo teórico, isto é, a habilidade de criar e explorar modelos geométricos que explicitem propriedades e procedimentos para produzir um efeito desejado no espaço. 
Figura 7

Estrutura Generalização/Metáfora
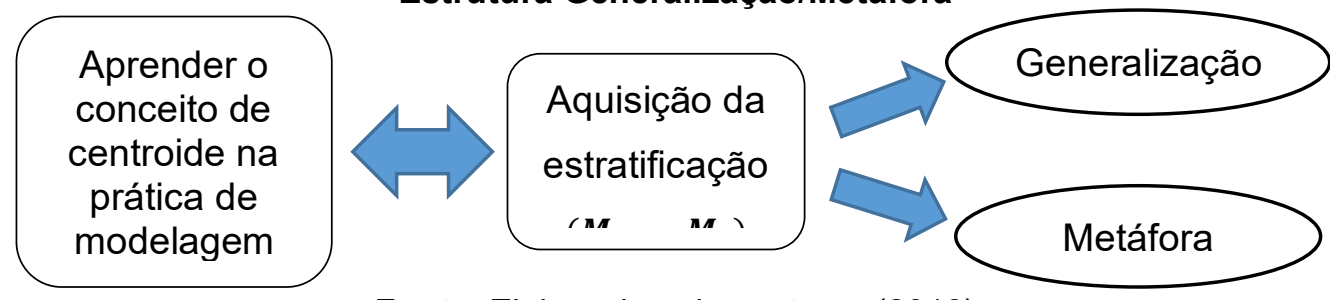

Fonte: Elaborado pelos autores (2018)

De fato, a noção de centroide de uma população obviamente se distingue de centroide de um polígono porque, enquanto no polígono o centroide ocupa uma posição média em relação a sua área, o centroide da população ocupa uma posição média em relação à localização de cada indivíduo. Se cada indivíduo de uma população pode ser identificado espacialmente pelas coordenadas $x$ e $y$, então as coordenadas $\bar{x}$ e $\bar{y}$ do centroide dessa população podem ser calculadas pela média aritmética das coordenadas $x$ e $y$ de todos os indivíduos dessa população. Mas, se uma população está distribuída em $n$ sub-regiões (bairros, cidades, escolas), de modo que o centroide da sub-região $i$, com $1 \leq i \leq n$, é localizado espacialmente pelas coordenadas $x_{i}$ e $y_{i}$ e o número de pessoas que vivem nessa sub-região é $w_{i}$, então, tomando cada valor de $w$ como um peso da sub-região $i$, a média ponderada das coordenadas $x$ e $y$ fornecem a localização do centro médio da população, isto é:

$$
\bar{x}=\frac{\sum_{i=1}^{n} w_{i} x_{i}}{\sum_{i}^{n} w_{i}} ; \quad \bar{y}=\frac{\sum_{i=1}^{n} w_{i} y_{i}}{\sum_{i}^{n} w_{i}}
$$

É importante notar que esse modo de calcular o centro médio de uma população pressupõe uma simplificação que não é exigida para o cálculo do centroide de uma figura geométrica. Essa simplificação exige que toda a população da sub-região $i$ vive concentrada no centroide dessa sub-região. Com isso, a variação na localização do centro médio da população de um país, por exemplo, fornece uma compreensão sobre como se dá a migração nesse país, pois o centro médio tem a propriedade de minimizar a soma dos quadrados das distâncias que as pessoas devem viajar para chegar ao centro médio.

Essas semelhanças e diferenças entre as noções de centroide e centro de uma população ajudam a entender o papel da noção de centroide como uma metáfora linguísticovisual na investigação do centro médio de uma população. Metáfora, no contexto da língua materna, é uma figura de linguagem que permite transferir o significado de uma palavra para 
outra. No contexto dessa prática de modelagem, quando os estudantes se inspiram na noção de centroide para investigar a noção de centro médio de uma população, eles também estão transferindo significados, porém utilizando uma metáfora linguístico-visual.

Esse intercâmbio de significados entre as noções de centroide e centro médio de uma população permite que elas sejam empregadas como um modelo geométrico para extrair informações do espaço tendo em vista promover um resultado desejado nesse espaço. Exemplos disso podem ser encontrados no estudo de fenômenos geográficos como acessibilidade e dispersão. Um estudo de acessibilidade busca investigar, por exemplo, a localização de equipamentos públicos de modo que sejam acessíveis à população.

Um estudo de dispersão que busca caracterizar a distribuição de uma população em torno de um ponto permite analisar a dispersão espacial dos indivíduos em torno de um local definido. Se a dispersão de indivíduos com uma certa doença, por exemplo, é menor em torno de um determinado local, isto pode significar que o risco de desenvolver essa doença é maior em posições próximas a esse local.

Em vista dessas considerações, parece razoável supor que a estrutura generalização/metáfora é a expressão de como a aprendizagem do conceito de centroide se dá na prática de modelagem, isto é, expressa o modo pelo qual os estudantes aprendem a extrair informações acerca do espaço e investigar o centro médio de uma população tendo em vista um resultado desejado de acessibilidade.

Nesse sentido, essa estrutura é também um modo pelo qual se dá a manifestação da habilidade $H_{6}$, pois a aquisição do conceito de centroide funciona como a aquisição de uma metáfora linguística-visual que torna possível a expressão dessa habilidade $H_{6}$; torna possível expressar e tornar objetiva uma compreensão acerca de um tema oriundo do espaço, assim como de outros domínios da matemática (área, média aritmética e média ponderada).

\section{Considerações finais}

Neste trabalho, ao analisar a aprendizagem da geometria em práticas de modelagem matemática a partir de um modelo teórico que mapeia essa aprendizagem em termos de dimensões ou habilidades, foi possível identificar como os estudantes aprendem a utilizar o conceito de centroide como um modo linguístico-visual de expressar e tornar objetiva uma compreensão acerca do espaço. Em particular, ao analisar como se manifesta a dimensão $H_{6}$, verificamos que a aprendizagem da noção geométrica de centroide se constitui e se mostra 
como a aquisição de uma metáfora linguística-visual com a qual os estudantes transportaram, interpretaram e extraíram informações acerca de uma população distribuição num mapa.

Desse modo, esse resultado corrobora os estudos de Almeida (2010) e Carreira (2001) que indicam que as metáforas, enquanto mecanismos cognitivos, realizam uma organização perceptiva que orienta a seleção consciente de aspectos específicos e particulares adequados para intercambiar significados também pode ser de grande valia para tratar da aprendizagem de geometria em práticas de modelagem e, particularmente, da noção do espaço em práticas dessa natureza.

Outro resultado deste trabalho a ser considerado aqui diz respeito ao uso do enfoque fenomenológico para abordar questões relativas à aprendizagem em práticas de modelagem matemática. Este enfoque traz à tona a possiblidade de considerar cenas significativas e discursos produzidos pelos estudantes para inquirir a aprendizagem em práticas de modelagem matemática sem precisar assumir previamente categorias teóricas acerca do investigado. No enfoque fenomenológico, é o próprio fenômeno que remete às suas categorias. Neste artigo, a estrutura que chamamos de generalização/metáfora não decorreu de categorias analíticas previamente definidas, mas se mostrou no próprio fenômeno da estratificação da aprendizagem do conceito de centroide.

Neste sentido, esse enfoque, ao mesmo tempo em que valida resultados de outras pesquisas, mostra novos modos de compreendê-las. Em pesquisas anteriores, Carreira et. al (2020), Levy (2016), Sousa e Almeida (2019) analisaram, a partir de quadros teóricos previamente definidos, as evidências da aprendizagem da matemática em práticas de modelagem. Essas evidencias, segundo esses estudos, estão ancoradas na análise de expressões linguísticas e/ou matemáticas produzidas pelos estudantes. A partir de uma abordagem fenomenológica é possível desvelar as estruturas subjacentes a essa aprendizagem, como é o caso da estrutura generalização/metáfora discutida neste trabalho.

\section{Referências}

Almeida, Lourdes Maria Werle. (2018). Considerations on the use of mathematics in modeling activities. ZDM - The International Journal on Mathematics Education, 50(1), 19-30.

Almeida, Lourdes Maria Werle. (2010). Um olhar semiótico sobre modelos e modelagem: metáforas como foco de análise. Zetetiké, Campinas, 18(temático), 387-414.

Almeida, Lourdes Maria Werle., Silva, Karina Pessôa da Silva. e Ramos, Daiany Cristiny. (2018). Sobre ensinar e aprender "o fazer" modelagem matemática. In Anais VII Seminário Internacional de Pesquisa em Educação Matemática. Foz do Iguaçu: Brasil. 
Almeida, Lourdes Maria Werle. e Vertuan, Rodolfo Eduardo. (2014). Modelagem matemática na educação matemática. In: Almeida, L. M. W.; Silva, K.A. P. Modelagem matemática em foco (pp. 19-43). Rio de Janeiro: Ed. Ciência Moderna Ltda.

Atiyah, Michael. (2003). What is geometry? In C. Pritchard (Ed.), The changing shape of geometry. Celebrating a century of geometry and geometry teaching (pp. 24-29). London: Cambridge University Press.

Bassanezi, Rodney Carlos. (2002). Ensino-aprendizagem com Modelagem Matemática. São Paulo: Contexto.

Bicudo, Maria Aparecida Viggiani. (2011). A pesquisa qualitativa olhada para além de seus procedimentos. In Maria Aparecida Viggiani Bicudo (Org.), Pesquisa Qualitativa segundo a visão fenomenológica (pp. 7-28). São Paulo: Cortez.

Bicudo, Maria Aparecida Viggiani (1994). Sobre a Fenomenologia. In Maria Aparecida Viggiani Bicudo, V.H.C. Esposito, (Org.), Pesquisa qualitativa em educação: um enfoque fenomenológico (pp. 15-22). Piracicaba: UNIMEP.

Blum, Werner. (2015). Quality teaching of mathematical modelling: What do we know, what can we do? In Sung Je Cho (Ed.), The Proceedings of the 12th International Congress on Mathematical Education (pp. 73-96). New York: Springer.

Carreira, Suzana. (2001). Where there's a model, there's a metaphor: metaphorical thinking in students' understanding of a mathematical model. Mathematical Thinking and Learning, 3(4), 261-287.

Carreira, Suzana., Baioa, Ana Margarida. e Almeida, Lourdes Maria Werle. (2020). Mathematical models and meanings by school and university students in a modelling task. AIEM - Avances de Investigación en Educación Matemática, (17), 67-83.

Català, Claudi Alsina. (2001) Geometría y realidad. En Aspectos didácticos de matemáticas, 8, (pp. 11-33). Zaragoza, España: Instituto de Ciencias de la Educación.

D'Amore, Bruno (2007). Epistemologia, Didática da Matemática e Práticas de Ensino. Boletim de Educação Matemática, 20(28). Recuperado de https://www.redalyc.org/pdf/2912/291221871010.pdf

Ferri, Rita Borromeo (2018). Learning how to teach mathematical modeling in school and teacher education. Springer.

Freudenthal, Hans. (1973). Mathematics as an educational task. Dordrecht: D. Reidel Publishing Company.

Galbraith, Peter. (2015). Modelling, education, and the epistemic fallacy. In Stillman, Gloria Ann, Blum, Werner e Biembengut, Maria Salett (Eds.), Mathematical modelling in education research and practice - cultural, social and cognitive influences (pp. 339-348). Heidelberg: Springer. 
Galbraith, Peter. (2012). Models of modelling: genres, purposes or perspectives. Journal of Mathematical Modelling and Application, 1(5), 3-16.

Giorgi, Amedeo. (2014). Sobre o método fenomenológico utilizado como modo de pesquisa qualitativa nas ciências humanas: teoria, prática e avaliação. Em Poupart, Jean et al., $A$ pesquisa qualitativa: enfoques epistemológicos e metodológicos (Trad. Ana Cristina Nasser, v. 2, pp. 386-409, 4a. ed.). Petrópolis: Vozes.

Girnat, Boris. e Eichler, Andreas. (2011). Secondary teachers' beliefs on modelling in geometry and stochastics. In Trends in teaching and learning of mathematical modelling (pp. 7584). Dordrecht: Springer.

Grigoraş, Roxana., Garcia, Francisco Javier. e Halverscheid, Stefan. (2011). Examining mathematising activities in modelling tasks with a hidden mathematical character. In Trends in teaching and learning of mathematical modelling (pp. 85-95). Netherlands: Springer.

Halverscheid, Stefan. (2008). Building a local conceptual framework for epistemic actions in a modelling environment with experiments. ZDM, 40(2), 225-234.

Hardy, Godfrey Harold. (2003). What is geometry? In C. Pritchard (Ed.), The changing shape of geometry. Celebrating a century of geometry and geometry teaching (pp. 13-19). London: Cambridge University Press.

Houdement, Catherine. and Kuzniak, Alain. (2003). Elementary geometry split into different geometrical paradigms. In Proceedings of European Research in Mathematics Education III. Working Group 7, 2003. Recuperado de http://www.mathematik.unidortmund.de/ erme/CERME3/Groups/TG7/TG7 Houdement cerme3.pdf

Husserl, Edmund. (2012). A crise das ciências europeias e a fenomenologia transcendental (DF Ferrer, Trad.). Rio de Janeiro, RJ: Forense Universitária.

Klüber, Tiago Emanuel. (2013). Aspectos relativos à noção de prática(s) de modelagem matemática na educação matemática. Florianópolis, 8(1), p. 92-103.

Levy, Lênio Fernandes. (2016). Pode-se aprender matemática através da investigação de casos particulares? Alexandria, 9(2), 287-301.

Mason, John. (2001). Modelling modeling: Where is the centre of gravity of-for-when teaching modelling. In J. Matos, W. Blum, S. Houston and S. Carreira (Eds.), Modelling and mathematics education. ICTMA, 9 (pp. 39-61). Chichester: Horwood Publishing.

Meyer, João Frederico da Costa., Caldeira, Ademir Donizetti. e Malheiros Ana Paula (2011). Modelagem em Educação Matemática. Belo Horizonte: Autêntica.

Pollak, Henry. (2015). The Place of Mathematical Modelling in the System of Mathematics Education: Perspective and Prospect. In Stillman, Gloria Ann, Blum, Werner e Biembengut, Maria Salett (Eds.), Mathematical Modelling in Education Research and Practice: cultural, social and cognitive influences (pp. 265-276). New York: Springer. 
Sokolowski, Robert. (2004). Introdução à fenomenologia. São Paulo: Edições Loyola.

Sousa, Bárbara Nivalda Palharini Alvim. e Almeida, Lourdes Maria Werle de Almeida. (2019). Apropriação Linguística e Significado em Atividades de Modelagem Matemática. Bolema, Rio Claro (SP), 33(65), 1195-1214.

Swan, Malcolm., Turner, Ross., Yoon, Caroline. e Muller, Eric. (2007). The roles of modelling in learning mathematics. In Blum, Werner, Galbraith, Peter and Niss, Moggens (Eds.), Modelling and applications in mathematics education: The 14th ICMI Study (pp. 275284). NY: Springer.

Thompson, Maynard. e Yoon, Caroline. (2007). Why build a mathematical model? Taxonomy of situations that create the need for a model to be developed. In Richard LESH, Eric HAMILTON e James KAPUT (eds.), Foundations for the Future in Mathematics Education (pp. 193-200), London: Laurence Earl Baum Associates.

Usiskin, Zalman. (1998). Resolvendo os dilemas permanentes da geometria escolar. In: Lindquist, M. M.; Shulte, A. P.(orgs). Aprendendo e ensinando geometria (Trad. de Hygino H.Domingues; pp. 21-39). São Paulo: Atual.

Zapata-Grajales, Fabio Nelson., Cano-Velásquez, Natalia Andrea. y Villa-Ochoa, Jhony Alexander. (2017). Art and geometry of plants: Experience in mathematical modelling through projects. Eurasia Journal of Mathematics, Science and Technology Education, 14(2), 585-603. Recuperado de https://www.ejmste.com/download/art-and-geometry-ofplants-experience-in-mathematical-modelling-through-projects-5286.pdf

Zukauskas, Nara Silvia Tramontina. (2012). Modelação matemática no ensino fundamental: motivação dos estudantes em aprender geometria (Dissertação Mestrado em Ciências e Matemática). Pontifícia Universidade Católica do Rio Grande do Sul, Porto Alegre, Brasil. 
Revista indizada en
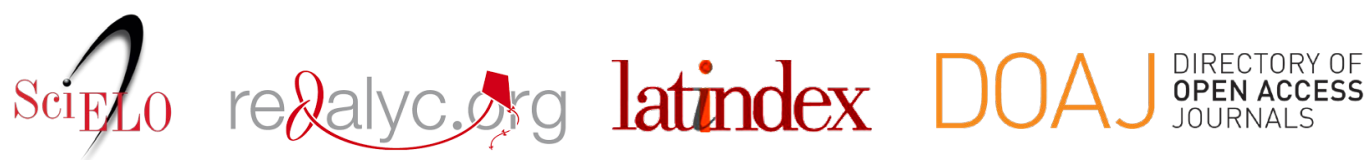

Distribuida en las bases de datos:

- Dialnet

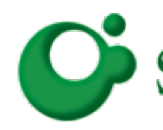
SHERPA/RøMEO

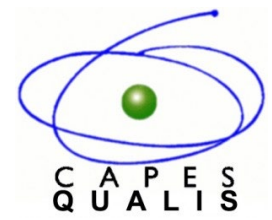

MIAR 